\title{
Toddler Stage
}

National Cancer Institute

\section{Source}

National Cancer Institute. Toddler Stage. NCI Thesaurus. Code C89890.

A human life stage that begins at thirteen months of age and continues until twenty-four complete months of age. 